\title{
Efeito do Tratamento de Sementes com Fungicidas sobre o Controle de Doenças na Parte Aérea do Trigo
}

\author{
Edson Clodoveu Picinini \& José Maurício Cunha Fernandes \\ Embrapa Trigo, Cx. Postal 569, CEP 99001-970, Passo Fundo, RS, e-mail: picinini@cnpt.embrapa.br
}

(Aceito para publicação em 14/05/2003)

Autor para correspondência: Edson Clodoveu Picinini

PICININI, E.C. \& FERNANDES, J.M.C. Efeito do tratamento de sementes com fungicida sobre o controle de doenças na parte aérea do trigo. Fitopatologia Brasileira 28:515-520. 2003.

\section{RESUMO}

O controle das doenças foliares do trigo (Triticum aestivum) através do tratamento de sementes foi avaliado em Passo Fundo, RS em 1999. A cultivar usada no experimento foi OR 1, conhecida por sua suscetibilidade ao oídio e à ferrugem da folha. Todos os fungicidas diferiram $(\mathrm{p} \geq 0,05)$ da testemunha, não tratada em rendimento de grãos (REND) e peso do hectolitro (PH). Os maiores rendimentos foram obtidos nos tratamentos fluquinconazole + procloraz nas doses de 250,0 g + 51,0 g e 125,0 g + 25,0 g (2.943 $\mathrm{kg} / \mathrm{ha} \mathrm{e} 2.864 \mathrm{~kg} / \mathrm{ha}$ ), 132 e $125 \%$, respectivamente, superiores ao rendimento da testemunha $(1.270 \mathrm{~kg} / \mathrm{ha})$. Os fungicidas triazóis indicados pela pesquisa (triticonazole, difenoconazole e triadimenol) produziram $1.908 \mathrm{~kg} / \mathrm{ha}, 1.821 \mathrm{~kg} / \mathrm{ha}$ e $1.815 \mathrm{~kg} / \mathrm{ha}$, respectivamente e não diferiram entre si. Não foram observados efeitos fitotóxicos dos tratamentos de sementes com os diferentes fungicidas e doses em teste. O controle do oídio (Blumeria graminis f. sp. tritici) e da ferrugem da folha (Puccinia triticina) foi efetivo até aos 98 DAE (dias após a emergência), a partir do qual atingiu-se o limiar indicado para pulverização na parte aérea recomendado. Aos 108 DAE os fungicidas começaram a perder a persistência e aos 118 DAE, as severidades médias de oídio e ferrugem, dos diferentes tratamentos, foram de $6,52 \%$ e $33,90 \%$ e o da testemunha de $16,5 \%$ e $78,0 \%$, respectivamente. $\mathrm{O}$ tratamento de sementes com fungicidas como demonstrado nesse trabalho, quando associado com rotação cultural e cultivares mais resistentes, poderá ter importante papel no controle das doenças foliares do trigo reduzindo o custo e a poluição ambiental.

Palavras-chave adicionais: Triticum aestivum, sementes, doenças, controle.

\section{ABSTRACT}

Effect of fungicide seed treatment to control foliar diseases of wheat

The control of wheat (Triticum aestivum) foliar diseases through seed treatment was evaluated in Passo Fundo, RS, during 1999. The cultivar used in the experiment was OR 1 which is known to be very susceptible to powdery mildew and leaf rust. The response variables yield and test weight were significant $(P>0.05)$ lower in the check than in the treatments. Highest yields were obtained with fluquinconazol + prochloraz at rates of $250.0 \mathrm{~g}+51.0 \mathrm{~g}(2,943 \mathrm{~kg} / \mathrm{ha})$ and $125.0 \mathrm{~g}+25.0 \mathrm{~g}(2,864 \mathrm{~kg} / \mathrm{ha})$ being, respectively, $132 \%$ and $125 \%$ higher than the yield in check $(1,270 \mathrm{~kg} / \mathrm{ha})$. While treatments with triticonazol, difenoconazol and triadimenol yielded $1,908 \mathrm{~kg} / \mathrm{ha}$,
$1,821 \mathrm{~kg} / \mathrm{ha}$ and $1,815 \mathrm{~kg} / \mathrm{ha}$, respectively. No phytotoxic effects due to fungicide treatments were observed. The powdery mildew and leaf rust control was effective up to $98 \mathrm{DAE}$ (days after emergency) which coincided with the threshold for fungicide spraying. Fungicides were no longer efficient after 108 DAE. Powdery mildew and leaf rust severity, at $118 \mathrm{DAE}$ in the treatments involving fluquinconazol + prochloraz were $6.2 \%$ and $33.9 \%$, and in the check $16.5 \%$ and $78.0 \%$, respectively. Thus, treating wheat seeds with fungicides, as demonstrated in this work, in association with crop rotations and more resistant cultivars may play an important role in controlling foliar diseases of wheat while reducing production costs and environmental polution.

\section{INTRODUÇÃO}

O auge da triticultura no Brasil foi alcançado no ano de 1987, quando foram semeados mais de 3,7 milhões de hectares, com a produção atingindo 6,2 milhões de toneladas. No ano de 1999, com uma área semeada de 1,4 milhões de hectares (Trigo, 2000), a produtividade média situou-se em $1.953 \mathrm{~kg} / \mathrm{ha}$. As doenças nos cereais de inverno se constituem em um fator importante atingindo diretamente o homem ao reduzir a qualidade e a quantidade dos grãos produzidos. Resultados de doze anos de investigação mostraram que a cultura do trigo (Triticum aestivum L.) pode perder, em média, nas condições do sul do Brasil, 44,6\% no rendimento de grãos (Picinini et al.,
1996). Os mesmos autores reportam, ainda, que o uso de fungicidas em trigo representa cerca de $27 \%$ do custo de produção, estimando-se que no ano de 2001 foram gastos o equivalente a 44 milhões de dólares com fungicidas na cultura.

Favorecidas pelas condições climáticas do sul do Brasil, doenças do trigo como o oídio, induzido por Blumeria graminis f. sp. tritici (Dc.). E.O.Speer, anamorfo: Oidium monilioides (Nees) Link, as ferrugens da folha e do colmo, induzidas por Puccinia triticina (Rob. Ex. Desm) e Puccinia graminis f. sp. tritici (Heriks. \& Henn.), respectivamente, a mancha da gluma, induzida por Phaeosphaeria nodorum [anamorfo: Stagonospora nodorum (Berk.) Cast. \& Germ.], a mancha marrom, induzida por Cochliobolus sativus (Ito \& Kurib), 
Dreschs. Ex Dastur. [anamorfo: Bipolaris sorokiniana (Sacc. In. Sorok) Shoem], a mancha amarela, induzida por Pyrenophora tritici-repentis (Died.) Drechs., [teleomorfo: rechslera tritici-repentis (Died. Shoemaker)] e a giberela, induzida por Gibberella zeae (Schw.) Petch [anamorfo: Fusarium graminearum (DC. ex. Mérrat)], estão entre as mais importantes. (Picinini \& Fernandes, 2000).

O oídio, segundo Linhares (1988), Fernandes et al. (1988) e Reis et al. (1997), pode ocasionar perdas de até $62 \%$ no rendimento de grãos de trigo. Para a ferrugem da folha, perdas de até $80 \%$ em rendimento de grãos na cultivar suscetível BR 34 foram relatadas por Picinini \& Fernandes (1994 e 1995).

Devido ao aumento na incidência e severidade das doenças fúngicas na cultura de trigo e na ausência da resistência genética ou de outro meio de controle mais eficaz, os fungicidas apresentam-se como alternativas para aumentar o potencial produtivo de trigo no Brasil (Reis \& Luz, 1976; Picinini \& Fernandes, 1988, 1992; Picinini et al., 1993).

As formas tradicionais de controle de doenças na cultura de trigo são através do uso de sementes tratadas que, segundo Machado (1988), é um dos métodos mais simples, de custo relativamente baixo e de reflexos altamente positivos para o aumento da produtividade, e pela pulverização com fungicidas na parte aérea, cuja eficiência do fungicida selecionado para o controle de uma doença específica é dependente do momento da aplicação e da qualidade da pulverização (Picinini \& Fernandes, 2000).

Objetivando controlar o oídio nos estádios iniciais de desenvolvimento da cultura na cultivar suscetível de trigo IAS 54 , testes foram realizados por Reis (1976a, e b), com sementes tratadas com o fungicida triadimefon, obtendo, em casa de vegetação, um período de proteção de 80 dias contra o fungo. Posteriormente, trabalhos realizados por Reis et al. (1977) e Fernandes et al. (1978) demonstraram o efeito do mesmo fungicida no controle de oídio e da ferrugem da folha no campo. Segundo Goulart (1999), com o advento dos fungicidas sistêmicos, principalmente do grupo químico triazol, duas das mais importantes doenças foliares do trigo (oídio e a ferrugem da folha) têm sido eficientemente controladas, durante os primeiros 45 dias de desenvolvimento vegetativo, através do tratamento de sementes. Martinelli (1995) relata que, em parcelas experimentais cujas sementes foram tratadas com o fungicida triadimenol, observou-se uma menor taxa de desenvolvimento inicial de ferrugem da folha, retardando a pulverização de fungicidas na parte aérea em até quinze dias. Segundo Azevedo (1996), quando a doença ocorre cedo, seu controle via tratamento de sementes é viável. Picinini \& Prestes (1996) relatam que o tratamento de sementes de trigo com fungicidas promove benefícios adicionais no controle de epidemias de ferrugem da folha e do oídio quando integrado ao tratamento da parte aérea. Este aspecto é importante nos programas de manejo integrado de controle de doenças.

O controle das doenças fúngicas da parte aérea via tratamento de sementes é uma nova alternativa, que, além da facilidade de uso e do menor risco de contaminação ambiental, poderá abrir novas perspectivas no controle das doenças em cereais de inverno no Brasil (Picinini \& Fernandes, 2001).

O presente trabalho teve como objetivo avaliar a eficiência de diferentes doses dos fungicidas triazóis recomendados para o tratamento de sementes de trigo, no controle de oídio e de ferrugem da folha na parte aérea da cultura.

\section{MATERIAL E MÉTODOS}

O experimento foi conduzido na área da Embrapa Trigo em Coxilha, RS, em 1999. Sementes da cultivar de trigo OR-1, suscetível ao oídio e à ferrugem da folha, foram tratadas no Laboratório de Fitopatologia da Embrapa Trigo, em Passo Fundo, RS, em frascos de Erlenmeyers de $2.000 \mathrm{ml}$ de capacidade. Os fungicidas (em g i.a./100 $\mathrm{kg}$ de sementes) + 2\% de água foram adicionados sobre as sementes, agitando-se vigorosamente até a completa cobertura das mesmas. Os fungicidas e doses usadas foram: fluquinconazole (3-(2,4-dichlorophenyl)-6flouro-2-(1- $H$-1,2,4-triazol-1-yl)quinazolin-4(3H)-one + procloraz (1- $N$-propyl- $N$-[2-(2,4,6-trichlorophenoxy)ethyl] imidazole-1carbocamide ), nas doses de 250,5 + 51,0;208,7 + 42,5; 167,0 + 34,0 e $125,5+25,5$, fluquinconazole, nas doses de 125,0 e de 83,0; triticonazole (1RS)-(E)-5-(chlorophenylmethylene)-2,2dimethyl-1-(1H-1,2,4-triazol-1-ylmethyl)-cyclopentan-1-ol), nas doses de 45,0; 90,0; 120,0 e 160,0; difenoconazole (cis, trans-3chloro-4-[4-methyl-2-(1H-1,2,4-triazol-1-ylmethyl)-1,3-dioxolan2-yl]phenyl 4-chlorophenyl ether), nas doses de 30,0; 60,0; 90,0; 120,0 e 150,0 e triadimenol (1 RS,2 RS; $1 R S, 2 S R)-1-(4-$ chlorophenoxy)-3,3-dimethyl-1-(1 H-1,2,4-triazol-1-yl)butan-2ol), nas doses de 40,0; 60,0; 80,0 e 100,0. Uma semeadora de precisão Wintersteiger foi usada na distribuição das sementes no campo em linhas de 5,0 m de comprimento espaçadas de 20 $\mathrm{cm}$ entre si. O solo foi previamente adubado com $250 \mathrm{~kg} / \mathrm{ha}$ da fórmula 5-25-25 (NPK). A adubação nitrogenada (uréia) foi realizada no início do perfilhamento. A dose usada foi de 150 $\mathrm{kg} / \mathrm{ha}$. O delineamento experimental foi o de blocos ao acaso com quatro repetições. As práticas culturais foram realizadas de acordo com a recomendação oficial (Reunião...1999). As variáveis medidas foram: rendimento de grãos (REND), severidade do oídio e da ferrugem da folha aos 22, 60, 70, 98, 108 e 118 dias após a emergência (DAE), peso do hectolitro $(\mathrm{PH})$, percentual de plantas emergidas aos 16 e 23 dias após a semeadura ( $\mathrm{PPE}^{1} \mathrm{e} \mathrm{PPE}^{2}$ ), a altura das plantas (AP) e o diâmetro do colmo (DC), avaliados aos 40 dias após a emergência (DAE). A colheita foi mecânica. Realizou-se a análise da variância dos dados de rendimento de grãos e a comparação entre as médias foi feita pelo teste de Duncan a 5\% de probabilidade.

\section{RESULTADOS E DISCUSSÃO}

\section{Rendimento de grãos e peso do hectolitro}

Os resultados (Tabela 1), mostram que, em rendimento de grãos REND, diferenças significativas ( $p \geq 0,05)$ entre os tratamentos foram observadas. As parcelas cujas sementes foram tratadas com fluquinconazole + procloraz, nas doses de 
Efeito do tratamento de sementes com fungicidas sobre o controle..

$250+51$ e $125+25$, produziram $2.943 \mathrm{~kg} / \mathrm{ha} \mathrm{e} 2.864 \mathrm{~kg} / \mathrm{ha}$, respectivamente, e foram $132 \%$ e $125 \%$ superiores ao rendimento da testemunha, sem tratamento $(1.270 \mathrm{~kg} / \mathrm{ha})$. A dose de $125+25$ do fungicida, no entanto, também não diferiu da dose de $208+42$, que produziu $2.581 \mathrm{~kg} / \mathrm{ha}$ e foi $103 \%$ superior ao REND da testemunha. A dose de $167+34$ da mistura estudada eqüivaleu-se ao fluquinconazole sozinho, testado nas doses de 83 e 125 e ao triticonazole, na dose de 160 . Os valores da variável REND foram de $2.437 \mathrm{~kg} / \mathrm{ha}, 2.315 \mathrm{~kg} / \mathrm{ha}$, $2.291 \mathrm{~kg} / \mathrm{ha}$ e $2.331 \mathrm{~kg} / \mathrm{ha}$, respectivamente. A produtividade de grãos nos demais tratamentos variou de $1.728 \mathrm{~kg} / \mathrm{ha}$ (triadimenol $100 \mathrm{~g} \mathrm{i.a} / 100 \mathrm{~kg}$ de sementes) a $2.006 \mathrm{~kg} / \mathrm{ha}$ (difenoconazole $120 \mathrm{~g}$ i.a/100 kg de sementes). Todos os tratamentos com fungicidas tiveram valores da variável REND superiores $(\mathrm{P}>0,05)$ à testemunha.

Os valores de peso do hectolitro $\mathrm{PH}$ foram relativamente baixos. Os fungicidas fluquinconazole + procloraz $(167+34 \mathrm{~g}$ i.a/100 kg de sementes) apresentou o maior valor (64,63 g) não diferindo de outros dez fungicidas comparados, que tiveram um pH médio de 63,32 g. Embora significante, a variação observada no peso do hectolitro do melhor tratamento e o da testemunha foi bastante pequena $(4,28 \mathrm{~g})$.

\section{Emergência, estatura de plantas e diâmetro do colmo.}

Vários são os sintomas de fitotoxicidade às plantas provocados por fungicidas do grupo dos triazóis, quando usados em tratamento de sementes. Reis (1976 b) destaca que o uso do fungicida triadimefon pode provocar uma coloração verde intensa das folhas, ápices foliares rombos e um nanismo generalizado da planta. Essa fitotoxicidade, segundo o autor, parece não influir negativamente sobre o rendimento de grãos. Outros sintomas característicos observados são a diminuição em maior ou menor grau, do mesocótilo, o que é dependente do produto usado, e a diminuição do número de plântulas emergidas.

O valor máximo de plântulas emergidas nas testemunhas, nas duas avaliações ( $\mathrm{PPE}^{1}$ e $\mathrm{PPE}^{2}$ ), realizadas aos 16 e aos 23 dias após a semeadura foram de 305 e 336, respectivamente. $\mathrm{Na}$ primeira avaliação, triadimenol, nas doses de 40 e $60 \mathrm{~g} \mathrm{i.a} / 100 \mathrm{~kg}$ de sementes com $89 \%$ e $95 \%$ de plântulas emergidas, igualaramse, estatisticamente, à testemunha. Nos demais, o percentual de emergência variou de $77 \%$ (fluquinconazole + procloraz $250 \mathrm{~g}+51 \mathrm{~g}$ ) a $86 \%$ (triadimenol $80 \mathrm{~g}$ ) em relação à emergência da testemunha e, praticamente, não diferiram entre si.

$\mathrm{Na}$ segunda avaliação, apenas os tratamentos triadimenol (60 g) e fluquinconazole ( $83 \mathrm{~g}$ ), com $91 \%$ e $90 \%$ de plântulas emergidas em relação à testemunha, igualaram, estatisticamente à esta. Nos demais, o percentual de emergência variou de $77 \%$ (triticonazole 45 e $160 \mathrm{~g}$ ) a $87 \%$ (fluquinconazole + procloraz $167+34 \mathrm{~g}$, fluquinconazole $125 \mathrm{~g}$, difenoconazole $60 \mathrm{~g}$ e triadimenol $80 \mathrm{~g}$ )

A AP da testemunha em relação às tratadas com os fungicidas comp arados foram pouco afetadas. A da testemunha, sem tratamento foi de $24,67 \mathrm{~cm}$. Entre os tratamentos, a AP variou de 22,06 cm (triticonazole $90 \mathrm{~g}$ ) a 25,81 cm (fluquinconazole 125 g). Uma possível redução na AP, proveniente de sementes tratadas e não tratadas com fungicidas do grupo dos triazóis, conforme observada por Reis (1976 b), não foi observada nesse trabalho. Esse fato deve-se, sem dúvida, ao fungicida usado pelo autor (triadimefon), sabidamente causador de efeitos marcantes nas plântulas em cereais de inverno. Fungicidas triazóis de nova geração, como o difenoconazole e o triticonazole, já não apresentam esta característica e/ou são menos perceptíveis. Sintomas como um verde intenso e brilhante, folhas mais largas, ápices rombos e a ausência de efeito no rendimento final de grãos das parcelas tratadas conforme relatado por Reis (1976 b), também foram observados nesse trabalho.

Embora significante $(\mathrm{p} \geq 0,05)$, as diferenças observadas na variável diâmetro da base do colmo (DC) da testemunha e do melhor tratamento (fluquinconazole + procloraz $250 \mathrm{~g}+51$ g) foi pequena $(0,22 \mathrm{~mm}$ e $0,28 \mathrm{~mm}$, respectivamente).

As pequenas diferenças observadas nas variáveis $\mathrm{PPE}^{1}$, $\mathrm{PPE}^{2}, \mathrm{APe} \mathrm{DC}$ provavelmente não se caracterizam por possíveis efeitos fitotóxicos nas plântulas emergidas das sementes tratadas com os diferentes fungicidas e doses comparados.

\section{Controle de doenças}

Os sintomas de oídio e de ferrugem da folha começaram a aparecer aos 42 DAE (Tabela 1). Aos 60 DAE, a testemunha, sem tratamento, apresentava severidade de oídio e de ferrugem da folha de $6,7 \%$ e $0,5 \%$, respectivamente. Entre os tratamentos, a maior severidade de oídio era do tratamento difenoconazole $30 \mathrm{~g}$ i.a/100 kg de sementes (2,3\%). As severidades progrediram e, aos 98 DAEobservou-se, na testemunha 13,4\% e 42,0\% de oídio e ferrugem da folha, respectivamente. As menores severidades das duas doenças foram a dos tratamentos que continham fluquinconazole. Quando em mistura com procloraz, a severidade média de oídio e de ferrugem da folha foi de 3,9\% e de $1,5 \%$. Quando usado isoladamente, a severidade média foi de $4,9 \%$ e $3,3 \%$, respectivamente. A eficiência do fungicida fluquinconazole, isoladamente e em mistura com o procloraz, no controle do da ferrugem da folha e da mancha bronzeada da folha na parte aérea através do tratamento de sementes já havia sido demonstrada por Picinini \& Fernandes (2001), onde, em experimentos realizados no ano de 1998 com a cultivar de trigo BR 43 observaram que decorridos 104 dias após a semeadura, a severidade da ferrugem foi $\leq$ a $18 \%$ em todos os tratamentos que continham o fungicida, contrastando com valores de $62 \%$ no tratamento comparativo. Para a mancha bronzeada, os tratamentos com fluquinconazole foram $\leq$ a $3 \%$ contrastando com valores $\geq$ a $34 \%$ nos tratamentos comparativos. Esse relato se constitui na primeira observação a campo de uma eficiência tão longa de um fungicida triazol usado em tratamento de sementes para o controle de ferrugem e de mancha bronzeada da folha de trigo. A eficiência do fluquinconazole no controle de oídio também já havia sido relatada por Stadnik et al 2000 que demonstraram que sementes tratadas com fluquinconazole inibiram completamente o desenvolvimento da doença na parte aérea da cultura, corroborando com resultados de Goulart (1999) de que fungicidas que aplicados à semente se transloquem para os órgãos aéreos da planta e lá permanecem por um longo 
Efeito do tratamento de sementes com fungicidas sobre o controle..

período podem oferecer proteção prolongada à entrada de patógenos. Considerando-se as recomendações da pesquisa de trigo para início do controle de oídio e de ferrugem da folha com fungicidas para a pulverização na parte aérea (Reunião...2000), observou-se no trabalho que somente a partir de 98 DAE seria alcançado índice recomendado para o controle químico dessas doenças. Considerando que o ciclo médio das cultivares de trigo recomendadas no RS até a fase de espigamento é de 87 dias (Reunião... 2000) e no Paraná de cerca de 72 dias (Reunião...2000), somente uma aplicação de fungicida para a proteção de doenças de espiga (se necessária) seria realizada. Esse fato é de extrema importância para a triticultura, considerando-se a alta suscetibilidade da cultivar em teste aos dois patógenos alvos (oídio e ferrugem da folha). Aos 98 DAE, pequenas diferenças foram observadas entre as doses de alguns tratamentos. A severidade média das quatro doses do fungicida triticonazole (recomendado oficialmente na dose de $45 \mathrm{~g}$ i.a. $/ 100 \mathrm{~kg}$ de sementes) foi, para oídio e para a ferrugem, de $8,6 \%$ e 9,4\%. Para as cinco doses do difenoconazole (recomendado oficialmente na dose de $30 \mathrm{~g}$ i.a. $/ 100 \mathrm{~kg}$ de sementes) foi de $8,6 \%$ e $8,6 \%$. Para as quatro dose de triadimenol (recomendado oficialmente na dose de 40 g i.a./100 kg), a severidade média de oídio foi de $8,4 \%$ enquanto para a ferrugem da folha foi de $16,5 \%$. A boa atividade dos fungicidas triadimenol e difenoconazole no controle de oídio é concorde com o trabalho de Goulart (1998 e 1999) que demonstrou que o melhor controle da doença foi obtido com o fungicida triadimenol seguido do difenoconazole.

Aos 108 DAE, observou-se aumento na severidade de oídio e da ferrugem da folha, indicando uma perda de persistência dos produtos em teste. Nessa oportunidade, o monitoramento das doenças a campo já teria detectado a ultrapassagem do índice indicado para o controle dessas doenças a campo conforme indicado na recomendação (Reunião...2002). Para o oídio, a severidade variou de 9,3\% ( fluquinconazole + procloraz ), na dose de $125 \mathrm{~g}+25 \mathrm{~g}$, a 14,2\% (difenoconazole ), na dose de $150 \mathrm{~g}$, igual à severidade da testemunha. Para a ferrugem da folha, os menores índices de severidade foram dos tratamentos fluquinconazole + procloraz, variando entre as doses de 4,8\% (125 g + $25 \mathrm{~g})$ e $12,7 \%(167+$ $34 \mathrm{~g})$. A severidade da ferrugem da folha no tratamento fluquinconazole, nas duas doses avaliadas ( $83 \mathrm{~g} \mathrm{e} 125 \mathrm{~g}$ ) foram semelhantes, $23,6 \%$ e $23,1 \%$, respectivamente. Entre os demais tratamentos e doses avaliadas, a severidade da ferrugem foi $\geq$ a $38,5 \%$. Aos 118 DAE, praticamente pouco ou quase nenhum efeito residual dos produtos em teste foram observados, demostrado pelo aumento da severidade da ferrugem da folha nos diferentes tratamentos.

Considerando-se as culturas de inverno como culturas de relativo risco, a minimização desse pelo emprego de fungicidas eficientes poderá contribuir sobre maneira para a estabilidade da lavoura, garantindo-se altos rendimentos. Enormes são as dificuldades em se determinar o melhor momento de iniciar o controle das doenças foliares em trigo. A confirmarem-se os resultados obtidos nesse trabalho, considerável avanço será obtido no controle de patógenos incitantes de doenças foliares. O tratamento de sementes com fungicidas eficientes, como aqui relatados, aliado a estratégias como a rotação cultural e o uso de cultivares mais resistentes, poderá reduzir para apenas uma (no florescimento da cultura) o número de pulverizações com fungicidas, diminuindo, consideravelmente, o custo de produção e o impacto ao ambiente.

\section{REFERÊNCIAS BIBLIOGRÁFICAS}

AZEVEDO, L.A.S. Tratamento de sementes com fungicidas visando o controle de patógenos na parte aérea. Simpósio Brasileiro de Patologia de Sementes, 4. 1996, Gramado, RS. Tratamento químico de sementes: anais. Campinas: Fundação Cargill, 1996. pp.83-91.

FERNANDES, J.M.C., PRESTES, A.M. \& NARDI, C.A. Tratamento de sementes no controle de doenças foliares do trigo, 10. Reunião Anual Conjunta de Pesquisa de Trigo. Porto Alegre, 1978.

FERNANDES, J.M.C., ROSA, O.S. \& PICININI, E.C. Perdas no potencial de rendimento de linhas quase isogênicas de trigo devidas ao oídio. Fitopatologia Brasileira 13:131. 1988 (Resumo).

GOULART, A.C.P. Controle do oídio e da ferrugem da folha pelo tratamento de sementes de trigo com fungicidas. Fitopatologia Brasileira 23:248. 1998 (Resumo).

GOULART, A.C.P. Controle do oídio e da ferrugem da folha pelo tratamento de sementes de trigo com fungicidas. Dourados: Embrapa Agropecuária Oeste, Boletim de Pesquisa, 1. 1999. 26p.

INFORMAÇÕES TÉCNICAS PARA A CULTURA DO TRIGO NO PARANÁ-2000. Londrina, IAPAR. Circular, 109. 2000.

LINHARES, W.I. Perdas de produtividade ocasionadas por oídio na cultura de trigo. Fitopatologia Brasileira 13:74-75. 1988.

MACHADO, J. da C. Patologia de sementes: fundamentos e aplicações. Brasília: MEC; Lavras: ESAL/FAEPE, 1988.

MARTINELLI, J.A. Controle da ferrugem da folha (Puccinia triticina) do trigo (Triticum aestivum) pelo tratamento de sementes e sua conseqüência sobre o tratamento aéreo convencional. Fitopatologia Brasileira 20:304. 1995 (Resumo).

PICININI. E.C. \& FERNDES, J.M.C. Ensaios preliminares e cooperativos de fungicidas- resultados obtidos no Centro Nacional de Pesquisa de trigo no período 1985-1987. Passo Fundo: EMBRAPA-CNPT, Documentos, 6. 1988.

PICININI. E.C. \& FERNDES, J.M.C. Ensaios preliminares e cooperativos de fungicidas- resultados obtidos no Centro Nacional de Pesquisa de trigo no período 1988-1991. Passo Fundo: EMBRAPA-CNPT, Documentos, 3. 1992.

PICININI, E.C. \& FERNANDES, J.M.C. Efeito da ferrugem da folha (Puccinia recondita f. sp. tritici) sobre o rendimento de grãos da cultivar de trigo BR 34 tratada com fungicidas. Fitopatologia Brasileira19:286p. 1994. (Resumo)

PICININI, E.C., FERNANDES, J.M.C. \& IGNACZAK, J.C. Effect of propiconazole spraiyng on yields of wheat and barley in southern Brazil during 1981 to 1992 . INTERNATIONAL CONGRESS OF PLANT PATHOLOGY, 6. Montreal, 1993. (Abstract).

PICININI, E.C. \& FERNANDES, J.M.C. Efeito de diferentes fungicidas sobre o rendimento de grãos, sobre o peso do hectolitro e sobre o controle da ferrugem da folha (Puccinia recondita $\mathrm{f}$. sp. tritici), em trigo, cultivar BR 34. Fitopatologia Brasileira 20:319. 
1995. (Resumo).

PICININI, E.C. \& PRESTES, A.M. Fungicidas recomendados para o tratamento de sementes de trigo. In: Simpósio brasileiro de patologia de sementes: anais, Campinas: Fundação Cargill, 1996. pp.58-63.

PICININI, E.C., FERNANDES, J.M.C., IGNAZACK, J.C. \& AMBROSI, I. Impacto econômico do uso do fungicida propiconazole na cultura do trigo (Triticum aestivum). Fitopatologia Brasileira 21:326-368. 1996.

PICININI, E.C. \& FERNANDES, J.M.C. Controle das doenças de trigo In: Cunha, G.R \& Bacaltchuk, B. Org. Tecnologia para produzir trigo no Rio Grande do Sul. Porto Alegre: Assembléia Legislativa. Comissão de Agricultura, Pecuária e Cooperativismo/Passo Fundo: Embrapa Trigo, Série Culturas, n²2. 2000.

PICININI, E.C. \& FERNANDES, J.M. Controle da ferrugem da folha e da mancha bronzeada da folha de trigo pelo uso de fungicidas em tratamento de sementes. Fitopatologia Brasileira 26:100. 2001. (Resumo)

REIS, E.M. Controle químico de Erysiphe graminis DC. f. sp.tritici Marshal, pelo tratamento de sementes. Summa Phytopathologica 2:209-213. 1976a.

REIS, E.M. Eficiência e persistência de fungicidas sistêmicos no controle de Erysiphe graminis tritici. Summa Phytopathologica 2:214-218. 1976b.

REIS, E.M. \& LUZ, W.C. da. Controle químico de doenças do trigo.
Reunião Anual Conjunta de Pesquisa de Trigo 8. Ponta Grossa, PR. 1976.

REIS, E.M., EICHLER, M.R. \& FERNANDES, J.M.C. Comportamento dos fungicidas triadimefon e KWG 0519 sobre plântulas de trigo e no controle de Erysiphe graminis f. sp. tritici pelo tratamento de sementes. Reunião Anual Conjunta de Pesquisa de Trigo 9. Londrina, 1977. 4v. Sanidade, pp.217-225.

REIS, E.M., CASA, R.T. \& HOFFMANN, L.L. Efeito de oídio causado por Erysiphe graminis f. sp. tritici, sobre o rendimento de grãos de trigo. Fitopatologia Brasileira 22:492-495. 1997.

REUNIÃO DA COMISSÃO SUL-BRASILEIRA DE PESQUISA DE TRIGO, 31., 1999, Passo Fundo. Recomendações... Comissão Sul-Brasileira de Pesquisa de Trigo, 1999.

REUNIÃO DA COMISSÃO SUL-BRASILEIRA DE PESQUISA DE TRIGO, 32., 2000, Cruz Alta. Recomendações... Comissão SulBrasileira de Pesquisa de Trigo, 2000.

REUNIÃO DA COMISSÃO SUL-BRASILEIRA DE PESQUISA DE TRIGO (34: Porto Alegre). Indicações Técnicas da Comissão Sul-Brasileira de Pesquisa de Trigo, 2002.

STADNIK, M.J., WILMSMEIER, B. EL-DEED, S. \& BUCHENAUER, H. Effect of fluquinconazole on the development of wheat powdery mildew. Fitopatologia Brasileira 25:427. 2000. (Resumo).

TRIGO. Indicadores da Agropecuária 9:12. 2000 